\title{
Activation of Mitogen-Activated Protein Kinases in the Non-Ischemic Myocardium of an Acute Myocardial Infarction in Rats
}

\author{
Ken Yoshida, MD; Minoru Yoshiyama, MD; Takashi Omura, MD; \\ Yasuhiro Nakamura, MD; Shokei Kim, MD*; Kazuhide Takeuchi, MD; \\ Hiroshi Iwao, MD*; Junichi Yoshikawa, MD
}

\begin{abstract}
As one of the signal transduction pathways related to myocardial remodeling, mitogen-activated protein kinases (MAPKs) possibly play an important role in ischemic heart disease, but it is still unknown whether myocardial MAPKs are activated in the non-ischemic region of an acute myocardial infarction (AMI). Therefore, the present study investigated the myocardial activity of extracellular signal-regulated kinases (ERKs), c-Jun $\mathrm{NH}_{2}$ terminal kinases (JNKs) and p38MAPK during the acute phase of an infarction of the rat heart, and measured the geometrical ventricular changes by echocardiography. All MAPKs were significantly activated in the ischemic myocardium (IM), non-ischemic septal wall (SW), and right ventricular wall (RV). Furthermore, the activation patterns of MAPKs differed in each region. The activation of p44ERK, JNKs and p38MAPK in the IM occurred rapidly after myocardial ischemia, followed by those in the SW and RV. The activator protein-1 DNA binding activities of the IM, SW and RV increased significantly at 1 day after coronary ligation. Echocardiography showed increased SW motion and RV dilatation. In conclusion, this is the first in vivo evidence that myocardial MAPKs are activated in the non-ischemic region of an AMI. Echocardiographic results suggest that acceleration of workload and/or stretch may partially induce the activation of MAPKs. (Jpn Circ J 2001; 65: 808-814)
\end{abstract}

Key Words: Acute myocardial infarction; c-Jun $\mathrm{NH}_{2}$ terminal kinases; Echocardiography; Extracellular signalregulated kinases; Mitogen-activated protein kinase; p38MAPK; Remodeling

$\Delta$ fter myocardial infarction (MI), contractile impairment in the ischemic myocardium (IM) occurs suddenly and the non-ischemic myocardium adapts to the increased workload. Thereafter, the myocardial properties and morphology begin to change as the ventricular remodeling during the clinical course. The ventricular remodeling is accompanied by progressive chamber dilatation and subsequently an increased incidence of sudden death and congestive heart failure!-5 In the IM, the structural rearrangement is characterized by myocardial cell damage, inflammatory change and expression of extracellular matrix components. Furthermore, ventricular dilatation and myocardial hypertrophy can occur in the non-ischemic regions. The process of ventricular remodeling after an acute myocardial infarction (AMI) involves topographical alternations in the ischemic and non-ischemic regions, ${ }^{1,2}$ so an understanding of the myocardial response to AMI is important for appropriate therapeutic management.

We previously reported that mitogen-activated protein kinases (MAPKs) are rapidly activated in the IM, followed by activation of transcriptional factors of activator protein 1 (AP-1) and mRNA expression of transforming growth factor $\beta$ - 1 , collagen types I and III, $\beta$-myosin heavy chain,

(Received November 27, 2000; revised manuscript received May 30, 2001; accepted June 5, 2001)

Departments of Internal Medicine and Cardiology, and *Pharmacology, Osaka City University Medical School, Osaka, Japan

Mailing address: Ken Yoshida, MD, Department of Internal Medicine and Cardiology, Osaka City University Medical School, 1-5-7 Asahimachi, Abeno-ku, Osaka 545-0051, Japan. E-mail: m1492122@ med.osaka-cu.ac.jp a -skeletal actin and atrial natriuretic peptide 7,8 MAPKs are a ubiquitous group of protein serine/threonine kinases and are important mediators of the signal transduction pathways responsible for cell growth, proliferation and apoptosis.-12 Therefore, this signal transduction system may be a key regulatory mechanism allowing cells to respond and eventually adapt to changes in myocardial ischemia. Although enhanced expression of the mRNAs was also observed in the non-ischemic region of the acutely infarcted heart, $7,8,13$ the corresponding activities of MAPKs in that region are still unknown. The present study investigated whether the signal-transduction pathway of the non-ischemic myocardium shifted to ventricular remodeling after AMI by examining the myocardial activities of extracellular signal-regulated kinases (ERKs), c-Jun $\mathrm{NH}_{2}$ terminal kinases (JNKs) and p38MAPK, plus the AP-1 DNA binding activities in both the ischemic and non-ischemic regions of an infarcted rat heart. Furthermore, to clarify the possible cause of MAPKs activation, we measured the geometrical changes of the infarcted heart using echocardiography and then estimated the stretch and workload of the infarcted heart.

\section{Methods}

\section{Production of the AMI}

Male Wistar rats weighing 290-310g (Clea Japan, Osaka, Japan) were used in the experiments. Myocardial infarction was produced as described previously?,8,14 Briefly, the rats were anesthetized by intraperitoneal injection of pentobarbital sodium $(35 \mathrm{mg} / \mathrm{kg})$. After intratracheal intubation, a left thoracotomy was performed under volume-controlled 
mechanical ventilation. The heart was raised from the thorax and a ligature with 6-0 prolene was placed around the proximal left anterior descending coronary artery, and then the chest was closed. The same surgical procedures were performed in sham-operated rats, except that the suture around the coronary artery was not tied.

\section{Preparation of Cardiac Protein Extracts}

For assay of the MAPKs, infarcted and sham-operated rats were decapitated at $0,5,15,30,60,120$, and $240 \mathrm{~min}$ after MI. The heart was rapidly removed and washed in precooled phosphate-buffered saline (PBS) (pH 7.4) containing $2.5 \mathrm{mmol} / \mathrm{L}$ ethylenediamine-N, N, N', N'-tetra-acetic acid (EDTA), $2 \mathrm{mmol} / \mathrm{L} \beta$-glycerophosphate, $10 \mathrm{mmol} / \mathrm{L} \mathrm{NaF}, 1$ $\mathrm{mmol} / \mathrm{L} \mathrm{Na} \mathrm{VO}_{4}$, and $1 \mathrm{mmol} / \mathrm{L}$ phenylmethylsulfonyl fluoride (PMSF) (each group: $n=4$ ). The IM of the left ventricles, the non-ischemic ventricular septal wall (SW) and the right ventricular free wall (RV) were homogenized on ice with a Polytron homogenizer (PCU-11, Kinematica, Littau/Luzern, Switzerland) in cell lysis buffer $(20 \mathrm{mmol} / \mathrm{L}$ HEPES (pH 7.2), $25 \mathrm{mmol} / \mathrm{L} \mathrm{NaCl}, 2 \mathrm{mmol} / \mathrm{L}$ ethylene glycol bis N, N, N', N'-tetra-acetic acid (EGTA), $0.2 \mathrm{mmol} / \mathrm{L}$

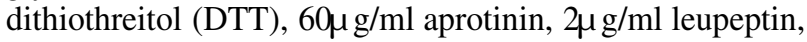
$1 \mathrm{mmol} / \mathrm{L} \mathrm{PMSF}$, $50 \mathrm{mmol} / \mathrm{L} \mathrm{NaF}, 1 \mathrm{mmol} / \mathrm{L} \mathrm{Na} 3 \mathrm{VO} 4$, and $25 \mathrm{mmol} / \mathrm{L} \beta$-glycerophosphate). After incubation at $4^{\circ} \mathrm{C}$ for $30 \mathrm{~min}$, the homogenates were sonicated (SONIFIER 250, Branson Ultrasonics Co, Danbury, CT, USA) on ice for $1 \mathrm{~min}$, and then centrifuged at $15,000 \mathrm{rpm}$ at $4^{\circ} \mathrm{C}$ for 30 min. After centrifugation, the supernatants were stored at $-80^{\circ} \mathrm{C}$ until use.

For the electrophoretic mobility shift assay, rats were decapitated 1 day after coronary ligation (each group: $n=4$ ). Nuclear protein extracts were prepared according to the method of Schreiber et al ${ }^{15}$ with minor modifications. About $100 \mathrm{mg}$ of myocardium was immediately washed in pre-cooled PBS (pH 7.4) containing $2.5 \mathrm{mmol} / \mathrm{L}$ EDTA, 2 $\mathrm{mmol} / \mathrm{L} \beta$-glycerophosphate, $10 \mathrm{mmol} / \mathrm{L} \mathrm{NaF}$ and $1 \mathrm{mmol} / \mathrm{L}$ $\mathrm{Na}_{3} \mathrm{VO}_{4}$, and homogenized with a Dounce homogenizer in $1 \mathrm{ml}$ of cold buffer (10 mmol/L HEPES (pH 7.9), $10 \mathrm{mmol} / \mathrm{L}$ $\mathrm{KCl}, 0.1 \mathrm{mmol} / \mathrm{L}$ EDTA, $0.1 \mathrm{mmol} / \mathrm{L}$ EGTA, $1.5 \mathrm{mmol} / \mathrm{L}$ $\mathrm{MgCl}_{2}, 10 \mathrm{mmol} / \mathrm{L} \mathrm{NaF}, 1 \mathrm{mmol} / \mathrm{L} \mathrm{Na} 3 \mathrm{VO}_{4}, 0.5 \mathrm{mmol} / \mathrm{L}$ PMSF, $1 \mathrm{mmol} / \mathrm{L}$ DTT, $20 \mathrm{mmol} / \mathrm{L} \beta$-glycerophosphate, 60 $\mu \mathrm{g} / \mathrm{ml}$ aprotinin, and $2 \mu \mathrm{g} / \mathrm{ml}$ leupeptin). The tissue homogenates were transferred into Eppendorf tubes and the cells were allowed to swell on ice for $15 \mathrm{~min}$, after which $62.5 \mu \mathrm{l}$ of $10 \%$ Nonidet P-40 was added and the tubes were vigorously vortexed for $10 \mathrm{~s}$. The nuclei were pelleted by centrifugation at $5,000 \mathrm{rpm}$ for $10 \mathrm{~min}$ at $4^{\circ} \mathrm{C}$. The nuclear pellets were resuspended in $150 \mu 1$ of cold buffer (20 mmol/L HEPES (pH 7.9), $0.4 \mathrm{~mol} / \mathrm{L} \mathrm{NaCl}, 1 \mathrm{mmol} / \mathrm{L}$ EDTA, $1 \mathrm{mmol} / \mathrm{L} \mathrm{EGTA}, 1.5 \mathrm{mmol} / \mathrm{L} \mathrm{MgCl}_{2}, 20 \%$ glycerol, 10 $\mathrm{mmol} / \mathrm{L} \mathrm{NaF}, 1 \mathrm{mmol} / \mathrm{L} \mathrm{Na3} \mathrm{VO}_{4}, 0.5 \mathrm{mmol} / \mathrm{L} \mathrm{PMSF}, 0.2$ $\mathrm{mmol} / \mathrm{L}$ DTT, $20 \mathrm{mmol} / \mathrm{L} \beta$-glycerophosphate, $60 \mu \mathrm{g} / \mathrm{ml}$ aprotinin, and $2 \mu \mathrm{g} / \mathrm{ml}$ leupeptin) and the tubes were rocked for $10 \mathrm{~min}$ at $4^{\circ} \mathrm{C}$. Following centrifugation at $15,000 \mathrm{rpm}$ for $10 \mathrm{~min}$ at $4^{\circ} \mathrm{C}$, the supernatants containing nuclear protein were collected and stored at $-80^{\circ} \mathrm{C}$ until use.

\section{Western Blot Analysis of ERKs and p38MAPK}

Protein extracts $(30 \mu \mathrm{g})$ from the hearts were separated on a $12 \%$ sodium dodecyl sulfate (SDS)-polyacrylamide gel and immobilized on polyvinylidene difluoride membrane. The membrane was immunoblotted with anti-phospho-ERK antibodies (Promega) using the ECL method in order to evaluate the phosphorylation of ERK. The same membrane was reblotted with anti-ERK antibodies (Santa Cruz Biotechnology, Inc, Santa Cruz, CA, USA) after stripping in order to evaluate the total amount of ERK. Western blot analysis using anti-phospho-p38MAPK antibodies and p38MAPK antibodies (New England Biolabs, Inc) was performed using the same procedure as for the ERKs.

An optical scanner (EPSON GT-8000, Seiko, Tokyo, Japan) was used for digitization of the Western blot analyses so that we could measure the phospho or total protein levels. The densities of each band in the digitized images in the same gel were measured using the public domain $\mathrm{NIH}$ Image program.

\section{In-gel Kinase Assay of JNK}

JNK activity was assayed using an in-gel kinase assay as described previously 8,16 JNK activity was estimated as the ability to phosphorylate glutathione-S-transferase

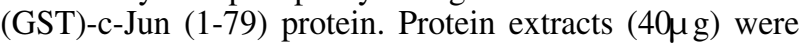
boiled for $5 \mathrm{~min}$ in Laemmli's sample buffer, and subjected to electrophoresis on SDS-polyacrylamide gels (12\%) containing $0.1 \mathrm{mg} / \mathrm{ml}$ of GST-c-Jun (1-79). After electrophoresis, the gels were incubated in $20 \%$ isopropanol containing $50 \mathrm{mmol} / \mathrm{L}$ Tris- $\mathrm{HCl}(\mathrm{pH} 8.0)$ twice for $30 \mathrm{~min}$, and then washed in $5 \mathrm{mmol} / \mathrm{L} 2$-mercaptoethanol containing $50 \mathrm{mmol} / \mathrm{L}$ Tris- $\mathrm{HCl}(\mathrm{pH} 8.0)$ twice for $30 \mathrm{~min}$. After denaturation of the kinases with $6 \mathrm{~mol} / \mathrm{L}$ guanidine-HCL, 5 $\mathrm{mmol} / \mathrm{L} 2-m e r c a p t o e t h a n o l$ and $50 \mathrm{mmol} / \mathrm{L}$ Tris- $\mathrm{HCl}(\mathrm{pH}$ 8.0) twice for $30 \mathrm{~min}$, the kinases in the gels were renatured by incubation in $0.04 \%$ Tween- $40,5 \mathrm{mmol} / \mathrm{L} 2$-mercaptoethanol and $50 \mathrm{mmol} / \mathrm{L}$ Tris- $\mathrm{HCl}(\mathrm{pH} 8.0)$ at $4^{\circ} \mathrm{C}$ for $12 \mathrm{~h}$, and then equilibrated in kinase buffer $(40 \mathrm{mmol} / \mathrm{L}$ HEPES (pH 7.5), $0.1 \mathrm{mmol} / \mathrm{L}$ EGTA, $20 \mathrm{mmol} / \mathrm{L} \mathrm{MgCl} 2$, and 2 $\mathrm{mmol} / \mathrm{L}$ DTT) twice for $30 \mathrm{~min}$. For the kinase reaction, the gels were incubated in kinase buffer with $25 \mu \mathrm{mol} / \mathrm{L}$ ATP and $925 \mathrm{kBq}(25 \mu \mathrm{Ci})(\gamma-32 \mathrm{P}) \mathrm{ATP}$ at $25^{\circ} \mathrm{C}$ for $1 \mathrm{~h}$. The reaction was terminated by washing the gels in $5 \%$ trichloroacetic acid and $1 \%$ sodium pyrophosphate. The gels were then dried and subjected to autoradiography. To estimate the kinase activity, the densities of bands on the autoradiograms were analyzed with a bioimaging analyzer (BAS-2000, Fuji Photo Film Co, Tokyo, Japan).

\section{Electrophoretic Mobility Shift Assays}

The sequence of the double-stranded oligonucleotide used in the present study was as follows ${ }^{17}$ : consensus AP-1, 5'-CGCTTGATGACTCAGCCGGAA-3'.

The oligonucleotide probes were labeled with $\left(\gamma-{ }^{32} \mathrm{P}\right)$ ATP at the 5' end, using T4 polynucleotide kinase, and the labeled probes were purified by chromatography on a BioSpin column (Bio-Rad, Richmond, CA, USA).

For the binding reactions, $5 \mu \mathrm{g}$ aliquots of nuclear extracts were incubated with probes and $2 \mu \mathrm{g}$ of poly (dIdC) (Pharmacia Biotech Inc, Uppsala, Sweden) in $20 \mu 1$ of binding buffer (20 mmol/L HEPES (pH 7.9), $1 \mathrm{mmol} / \mathrm{L}$ DTT, $80 \mathrm{mmol} / \mathrm{L} \mathrm{NaCl}, 0.2 \mathrm{mmol} / \mathrm{L}$ EDTA, $0.2 \mathrm{mmol} / \mathrm{L}$ EGTA, $0.3 \mathrm{mmol} / \mathrm{L} \mathrm{MgCl} 2,0.1 \mathrm{mmol} / \mathrm{L} \mathrm{PMSF}$, and $10 \%$ glycerol) for $15 \mathrm{~min}$ at room temperature. The reaction mixtures were then loaded onto $4 \%$ nondenaturing polyacrylamide gel in $6.7 \mathrm{mmol} / \mathrm{L}$ Tris- $\mathrm{HCl}(\mathrm{pH} 7.5), 3.3 \mathrm{mmol} / \mathrm{L}$ sodium acetate, $1 \mathrm{mmol} / \mathrm{L}$ EDTA, and $2.5 \%$ glycerol. Electrophoresis was performed at $200 \mathrm{~V}$ in $6.7 \mathrm{mmol} / \mathrm{L}$ Tris- $\mathrm{HCl}$ (pH 7.5), $3.3 \mathrm{mmol} / \mathrm{L}$ sodium acetate, $1 \mathrm{mmol} / \mathrm{L}$ EDTA at $4^{\circ} \mathrm{C}$. The gels were dried and subjected to autoradiography. To demonstrate the specificity of DNA-protein binding, the reactions were performed in the presence of non-labeled 

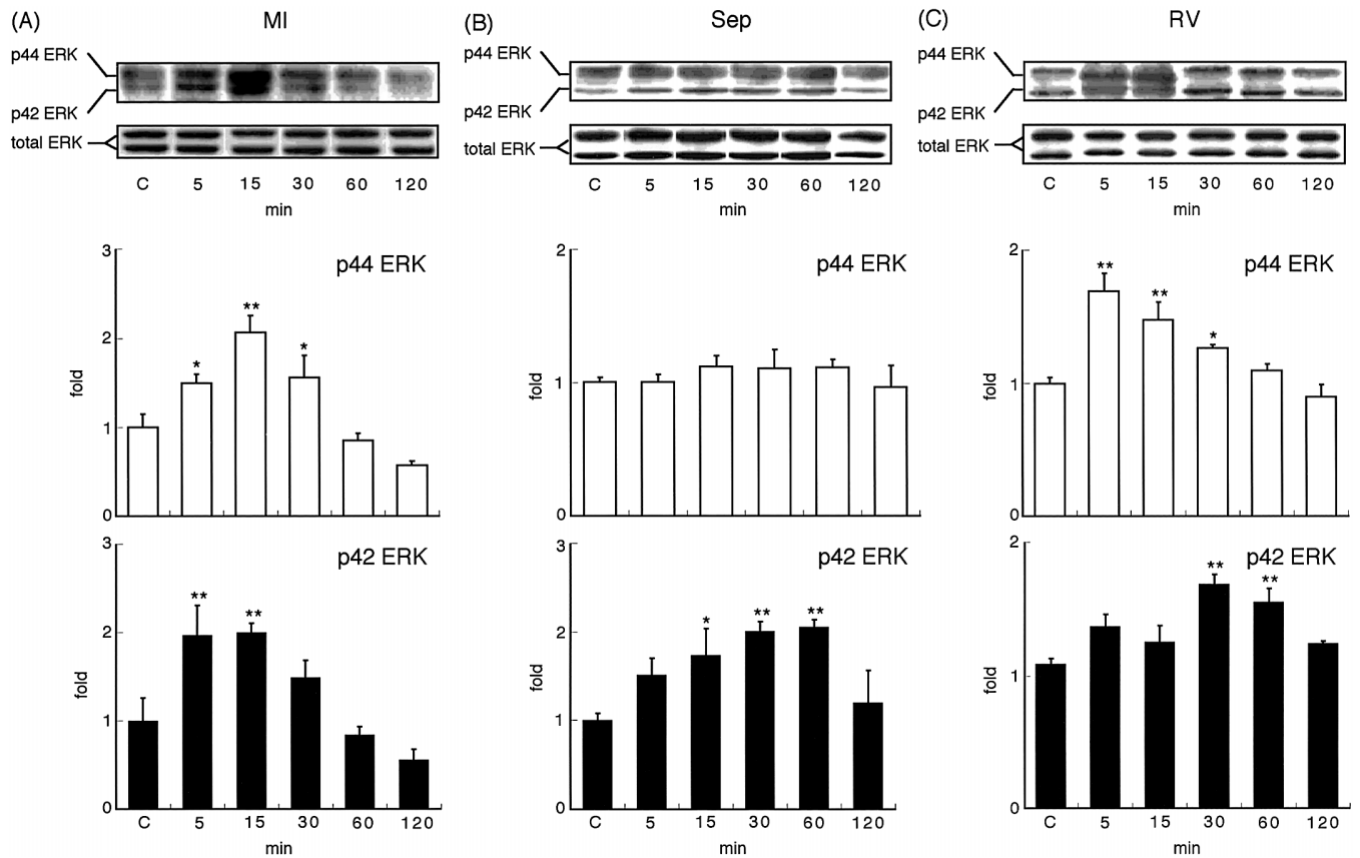

Fig 1. ERKs activity in ischemic myocardium (A), non-ischemic septal wall (B) and right ventricle (C) at 0, 5, 15, 30, 60, and $120 \mathrm{~min}$. (Upper panel) Representative Western blot analysis showing the phosphorylated and total amounts of $\mathrm{p} 44$ and p42ERK on at least 3 occasions. The mean value of the activities at $0 \mathrm{~min}$ is 1 . Values are means $\pm \mathrm{SE}(\mathrm{n}=4)$. $* \mathrm{p}<0.05$ and $* * \mathrm{p}<0.01$ vs Control $(0 \mathrm{~min})$.

consensus oligonucleotide competitors. In addition, a supershift assay for AP-1 was carried out using rabbit polyclonal IgG against c-Fos or c-Jun (Santa Cruz Biotechnology Inc) to examine the AP-1 complex containing c-Fos and c-Jun. Specific antibodies were added to samples after the initial binding reaction between nuclear protein extracts and ${ }^{32} \mathrm{P}-$ labeled consensus oligonucleotide, and the reaction was incubated at room temperature for $1 \mathrm{~h}$.

\section{Echocardiographic Studies}

After ligating the proximal left anterior descending coronary artery, the acute ventricular geometrical changes were estimated by trans-myocardial echocardiography $(n=5)$ using a commercially available echocardiographic system equipped with a 12-MHz phased-array transducer (Agilent Technologies, SONOS 5500). A 2-dimensional short-axis view of the left ventricle (LV) was obtained at the level of the papillary muscles. M-mode tracings were recorded through the anterior and posterior LV walls at a paper speed of $100 \mathrm{~mm} / \mathrm{s}$. The anterior and posterior end-diastolic and end-systolic wall thicknesses and the LV internal dimensions were measured on the M-mode tracings from at least 3 consecutive cardiac cycles, using the leading-edge method of the American Society for Echocardiology (ASE). Additionally, to measure the chamber size of the left and right ventricles, we also performed contrast echocardiography in another set of rats. After exposure of a femoral vein, we introduced a silicone catheter with an outer diameter of $0.8 \mathrm{~mm}$ and inner diameter $0.5 \mathrm{~mm}$ for injection of $0.15 \mathrm{ml}$ of Optison (Chugai Pharmaceutical Co, Ltd, Tokyo, Japan). Before and after left anterior descending artery coronary ligation, contrast echocardiography was performed and the 2-dimensional area of the left and right ventricles was measured.

\section{Statistics}

The results are expressed as means \pm SE. Statistical significance was determined using the unpaired Student's ttest or ANOVA. Differences were considered statistically significant when $\mathrm{p}<0.05$.

\section{Results}

\section{Activation of Myocardial ERK}

The phosphorylated activities of p42/p44ERK in the infarcted ventricular myocardium increased significantly at 5 min (1.97-fold; $\mathrm{p}<0.01$ and 1.5 -fold; $\mathrm{p}<0.05$ ), reached a peak at $15 \mathrm{~min}(2.0$-fold and 2.1 -fold; $\mathrm{p}<0.01)$ after coronary ligation, and decreased to the control level by $60 \mathrm{~min}$ (Fig 1A). Although the activity of p44ERK did not change with time in the SW, it increased gradually and reached a peak at 60 min $(2.1$-fold; $p<0.01)$ after coronary ligation (Fig 1B). In the RV, the phosphorylated activities of p42ERK and p44ERK increased significantly at $30 \mathrm{~min}$ $(1.7$-fold; $\mathrm{p}<0.01)$ and at 5 min $(1.7$-fold; $\mathrm{p}<0.01)$, respectively, after coronary ligation (Fig 1C). There were no significant changes in the ERK activities in the sham-operated rats at the same time points (data not shown).

\section{Activation of Myocardial p38MAPK}

The p38MAPK activity of the IM was increased at $5 \mathrm{~min}$ (4.4-fold; $\mathrm{p}<0.01$ ) and decreased to the control level by 60 min (Fig 2A). In the SW, p38MAPK activity gradually increased and reached a peak at $60 \mathrm{~min}$ (2.6-fold; $\mathrm{p}<0.01$; Fig 2B), and in the RV, it had increased markedly at $15 \mathrm{~min}$ (2.1-fold; $\mathrm{p}<0.05$; Fig 2C). There were no significant changes in the p38MAPK activities in the sham-operated rats at the same time points.

\section{Activation of Myocardial JNK}

The p46/p55JNK activity of the IM increased signifi- 
(A)
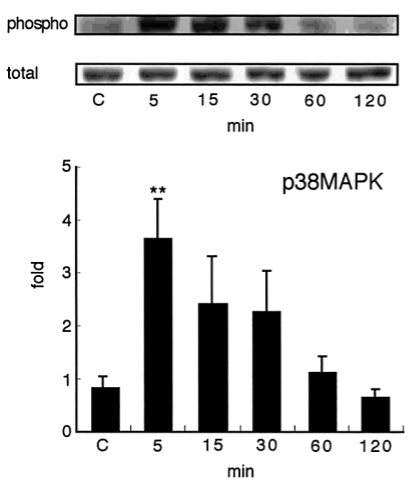

(B)

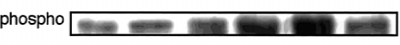

total
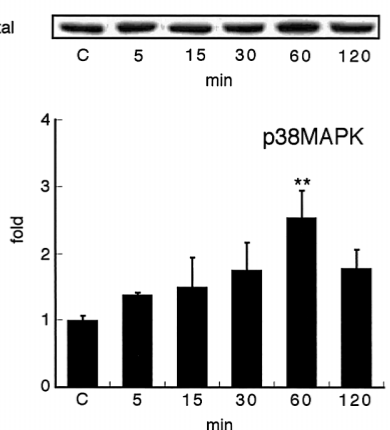

(C)
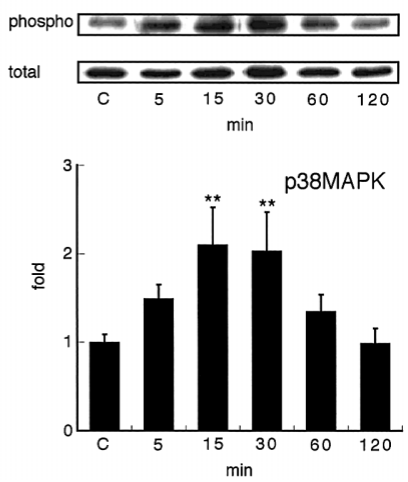

Fig 2. p38MAPK activities in ischemic myocardium (A), non-ischemic septal wall (B) and right ventricle (C) at 0, 5, 15, 30, 60, and $120 \mathrm{~min}$. (Upper panel) Representative Western blot analysis showing phosphorylated and total amounts of p38MAPK on at least 3 occasions. The mean value of the activities at $0 \mathrm{~min}$ is presentated as 1 . Each value is represent mean $\pm \operatorname{SE}(n=4) . * * p<0.01$ vs Control $(0 \mathrm{~min})$.

(A)
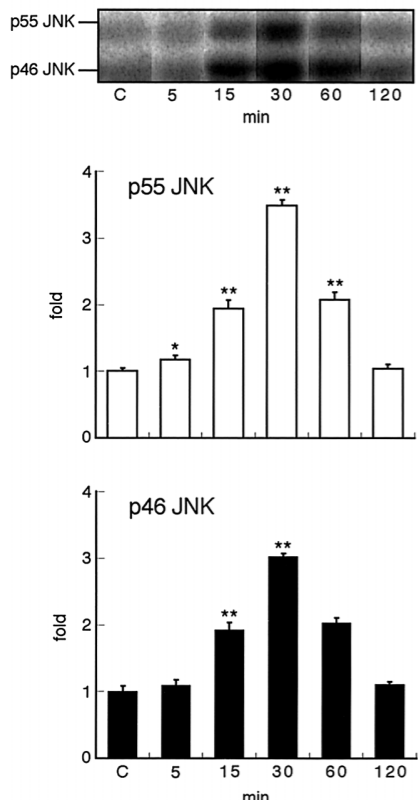

(B)
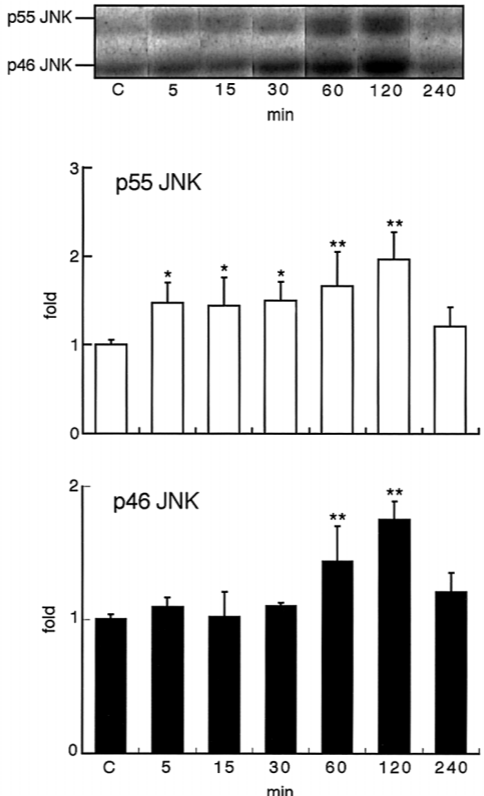

(C)
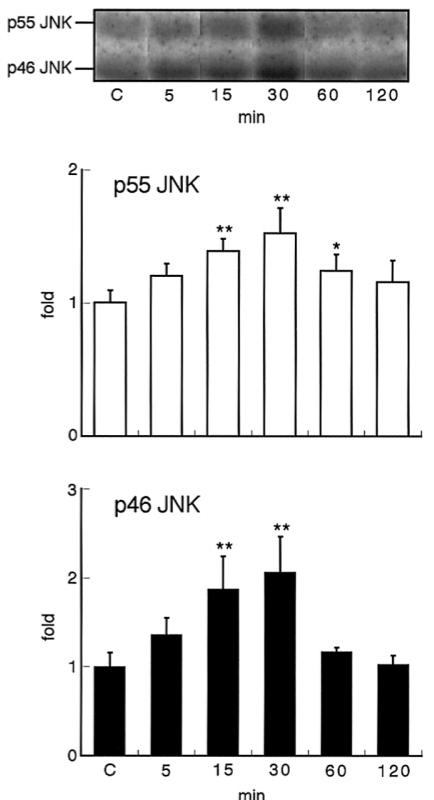

Fig 3. JNKs activities in ischemic myocardium (A), non-ischemic septal wall (B) and right ventricle (C) at $0,5,15,30$, 60,120 , and $240 \mathrm{~min}$. (Upper panel) Representative autoradiograms showing p46 and p55JNK activities by in-gel kinase assay performed at least 3 times. The mean value of the activities at 0 min is 1 . Values are means $\pm \mathrm{SE}(\mathrm{n}=4)$. ${ }^{*} \mathrm{p}<0.05$ and $* * \mathrm{p}<0.01$ vs Control $(0 \mathrm{~min})$.
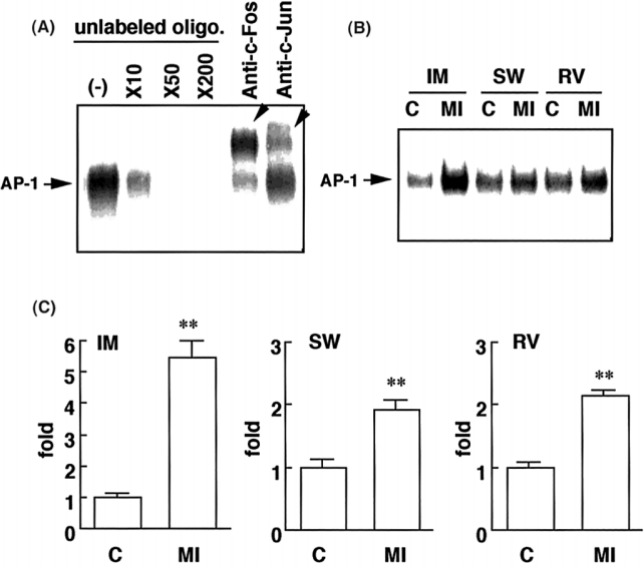

Fig 4. Specificity of AP-1 DNA binding activity from ischemic myocardium (A). Myocardial protein extracts, collected 1 day after coronary ligation, were incubated with a ${ }^{32} \mathrm{P}-$ labeled AP-1 oligonucleotide probe in the absence of unlabeled AP-1 oligonucleotide probe $(-)$, and in the presence of 10-, 50- and 200-fold molar excess of unlabeled AP-1 probe $(\times 10, \times 50$ and $\times 200)$. Supershift assays were performed with antic-Fos IgG (anti-c-Fos) and anti-c-Jun IgG (anti-c-Jun). Arrows show the supershifted bands by anti-c-Fos and anti-c-Jun. Myocardial AP-1 DNA binding activity in the ischemic myocardium (IM), non-ischemic septal wall (SW), and right ventricle (RV) 1 day after myocardial infarction (B). The mean value of the activities in the sham-operated rats $(C)$ is $1(n=4)$. MI, myocardial infarcted rats. Values are means \pm $\mathrm{SE}(\mathrm{C}) . * * \mathrm{p}<0.01$ vs sham-operated rats. 
Table 1 Echocardiographic Mesurements in the Acutely Infarcted Rat Heart

\begin{tabular}{lcccccc}
\hline \hline & Control & \multicolumn{5}{c}{ MI } \\
\cline { 3 - 6 } & & $5 \mathrm{~min}$ & $15 \mathrm{~min}$ & $30 \mathrm{~min}$ & $60 \mathrm{~min}$ & $120 \mathrm{~min}$ \\
\hline LVDd $(\mathrm{mm})$ & $5.23 \pm 0.26$ & $4.76 \pm 0.19$ & $5.13 \pm 0.39$ & $4.57 \pm 0.57$ & $4.68 \pm 0.46$ & $4.72 \pm 0.34$ \\
LVDs $(\mathrm{mm})$ & $3.17 \pm 0.23$ & $3.44 \pm 0.26$ & $3.82 \pm 0.35$ & $3.57 \pm 0.5$ & $3.53 \pm 0.28$ & $3.30 \pm 0.29$ \\
AW thickness $(\%)$ & $53 \pm 5$ & $0 \pm 3^{*}$ & $0 \pm 5^{* *}$ & $0 \pm 3^{* *}$ & $0 \pm 3^{* *}$ & $0 \pm 3^{* *}$ \\
$P W$ thickness $(\%)$ & $50 \pm 4$ & $52 \pm 3$ & $61 \pm 4$ & $68 \pm 5^{*}$ & $66 \pm 6^{*}$ & $64 \pm 3$ \\
LVAd $\left(\mathrm{cm}^{2}\right)$ & $0.17 \pm 0.01$ & $0.17 \pm 0.02$ & $0.17 \pm 0.03$ & $0.17 \pm 0.04$ & $0.17 \pm 0.03$ & $0.18 \pm 0.02$ \\
LVAs $\left(\mathrm{cm}^{2}\right)$ & $0.05 \pm 0.01$ & $0.08 \pm 0.02$ & $0.09 \pm 0.02$ & $0.10 \pm 0.03$ & $0.10 \pm 0.02$ & $0.11 \pm 0.01$ \\
LVAFS $(\%)$ & $68 \pm 3$ & $54 \pm 4^{* *}$ & $48 \pm 2 * *$ & $46 \pm 2^{* *}$ & $44 \pm 3^{* *}$ & $42 \pm 1^{* *}$ \\
RVAd $\left(\mathrm{cm}^{2}\right)$ & $0.07 \pm 0.01$ & $0.11 \pm 0.01^{*}$ & $0.13 \pm 0.02^{* *}$ & $0.13 \pm 0.02^{* *}$ & $0.13 \pm 0.01^{* *}$ & $0.14 \pm 0.01^{* *}$ \\
RVAs $\left(\mathrm{cm}^{2}\right)$ & $0.03 \pm 0.00$ & $0.05 \pm 0.01$ & $0.05 \pm 0.01$ & $0.06 \pm 0.01 *$ & $0.07 \pm 0.01^{*}$ & $0.07 \pm 0.01^{*}$ \\
RVAFS $(\%)$ & $51 \pm 5$ & $58 \pm 4$ & $55 \pm 5$ & $55 \pm 5$ & $51 \pm 8$ & $50 \pm 5$ \\
\hline
\end{tabular}

Compred with $*_{p}<0.05,{ }^{*} p<0.01$ to control. LV, left ventricle; RV, right ventricle; Dd, diameter in diastole; $A W$, anterior wall; $P W$, posterior wall; Ad, area in diastole; As, area in systole; AFS, area fractional shortening; MI, myocardial infarction.
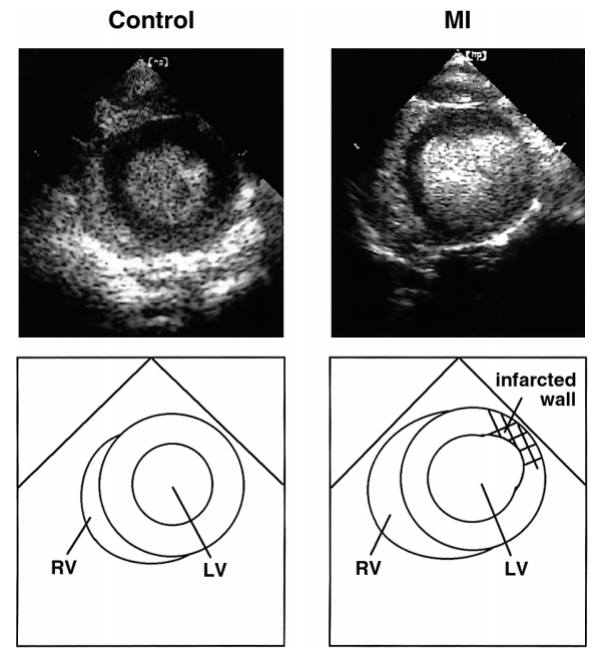

Fig 5. Representative contrast enhancement echocardiogram from a sham-operated (control) and myocardial infarction rat (MI). The 2dimensional short-axis view during the systolic phase of the heart was obtained at the level of papillary muscles and filled with Optison, an echo-enhanced contrast agent. (Lower panel) The schema of the control and MI.

cantly at $15 \mathrm{~min}(1.9$-fold and 1.9 -fold; $\mathrm{p}<0.01)$ and reached a peak at $30 \mathrm{~min}$ after coronary ligation (Fig $3 \mathrm{~A}$ ). In the $\mathrm{SW}, \mathrm{p} 46 / \mathrm{p} 55 \mathrm{JNK}$ activity gradually increased and reached a peak at $120 \mathrm{~min}(2.0$-fold and 1.5 -fold; $\mathrm{p}<0.01)$ after coronary ligation, and decreased to the control level by 240 $\min$ (Fig 3B). In the RV, the activities of JNKs increased at 15 min $(1.9$-fold and 1.4 -fold; $\mathrm{p}<0.01)$ after coronary ligation, then decreased to the control level by $120 \mathrm{~min}$ (Fig 3C). There were no significant changes in the JNKs activities in the sham-operated rats at the same time points.

\section{AP-1 DNA Binding Activity of the Nuclear Extracts}

The incubation of nuclear protein with ${ }^{32}$ P-labeled consensus AP-1 oligonucleotide resulted in the formation of one broad band (Fig 4), and this shifted band was certified to be specific for AP-1 because the additional unlabeled AP- 1 consensus oligonucleotide resulted in a decrease in the intensity of the band. The addition of anti-Fos or antiJun antibody reduced the intensity of the bands, and both antibodies induced the appearance of supershifted bands. AP-1 DNA binding activity in the IM, non-ischemic SW and the RV increased 5.5-fold $(\mathrm{p}<0.01), 1.9$-fold $(\mathrm{p}<0.01)$ and 2.2-fold ( $\mathrm{p}<0.01)$, respectively, at 1 day after coronary ligation.

\section{Echocardiographic Assessments of the LV and RV}

The geometry and function of the LV and RV are shown in Table 1. During the time course of the echocardiographic assessment of AMI, the percent thickness of the ventricular wall significantly decreased in the anterior wall at $5 \mathrm{~min}$ and increased in the posterior wall at $1 \mathrm{~h}(1.4$-fold; $\mathrm{p}<0.01)$. These results suggest that the wall motion of the IM was akinetic and that of the non-infarcted ventricular wall was hyperkinetic. As a further study, we used an echo contrast agent and estimated the morphological changes. Although the LV diastolic area did not change after AMI, the RV diastolic area increased. In contrast, the LV area fractional shortening decreased and that of the RV did not change, which shows that systolic function was significantly reduced in the LV and that the RV wall was mechanically stretched (Fig 5).

\section{Discussion}

The present study is the first to show the following in vivo evidence in rat hearts.

(1) ERKs, JNKs and p38MAPK in the non-ischemic SW and RV of the infarcted heart are activated after coronary artery ligation, followed by activation of AP- 1 transcriptional factors.

(2) Differential time courses of activation of MAPKs are observed in the IM, non-infarcted SW and RV.

(3) Echocardiography demonstrated akinetic motion in the anterior IM, hyperkinetic motion in the non-ischemic ventricular wall and dilatation of the RV in AMI.

The MAPK superfamilies (MAPKs) are activated by various extracellular stimuli and they mediate cellular hypertrophy and/or apoptosis in cardiac myocytes ${ }^{10-12,16,18-24}$ For example, in cultured neonatal rat ventricular myocytes, MAPKs are activated by growth factors such as angiotensin II, endothelin-1 anda-adrenergic agonists, and by cellular stress such as ultraviolet irradiation, reactive oxygen species, mechanical stretch, electrical pacing, and hyperosmotic shock ${ }^{25-32}$ Regarding ischemic heart disease, we previously reported that myocardial ERKs, JNKs and p38MAPK are activated in the infarcted myocardium of rat hearts, followed by activation of AP-1 and increased mRNA expression of transforming growth factor $\beta-1$, collagen types I and III, atrial natriuretic peptide, $\beta$-myosin heavy chain, and $\alpha$-skeletal actin? In addition, we also 
reported increased mRNA levels fora-skeletal actin, atrial natriuretic peptide, collagen types I and III in the noninfarcted myocardium 2 days after the infarction. However, at the time of that report, the activities of MAPKs in the non-ischemic region of the acutely infarcted heart were still unknown, but the upregulation of myocardial mRNA expression followed by cardiac remodeling encouraged us to examine the activities of MAPKs and AP-1 in the noninfarcted myocardium. In the present study, we demonstrated that ERKs, JNKs and p38MAPK were activated in the non-ischemic SW and RV of a rat heart infarcted after coronary artery ligation, thereby suggesting that MAPKs are involved in the myocardial molecular response immediately after coronary occlusion. Furthermore, the time course for the activation of MAPKs differed in the IM, non-ischemic SW and RV myocardium. In the IM, accompanied by inflammatory changes, the increase in MAPKs activity occurred earlier than in the non-ischemic myocardium and RV. The peak activities of p44ERK, JNKs and p38MAPK in the IM occurred more rapidly than in the non-ischemic myocardium and RV. Thereafter, the peak activity of MAPKs in the RV were observed, followed by the peak activity in the septal myocardium. These results suggest that each MAPK family is activated by different mechanisms in the ischemic and non-ischemic regions after MI, but the activation mechanisms of myocardial MAPKs in the non-infarcted myocardium after AMI were unclear from our study.

There is accumulated evidence that neurohumoral factors, such as the renin-angiotensin system and catecholamines, are activated during AMI in humans and play an important role in cardiac remodeling and/or the prognosis after MI ${ }^{33,34}$ In addition, angiotensin II and $\alpha$ - or $\beta$-adrenergic agonists activate myocardial MAPKs in the in-vivo rat heart $3^{5}$ Therefore, the activation of MAPKs in the noninfarcted LV and RV may be partially mediated by neurohumoral factors. On the other hand, mechanical stress induces the phosphorylation of all MAPKs in cultured cardiomyocytes 30 Moreover, myocardial MAPKs are activated in the hearts of rats with pressure overload and spontaneous hypertension?23,36 These studies support a possible role for mechanical stress in the in-vivo activation of myocardial MAPKs. To elucidate this role, we used echocardiography with an echo contrast agent to record the morphological changes of the infarcted heart because other studies have shown that contrast-enhanced echocardiography improves both the detection of the borders of the ventricular chambers and the evaluation of ventricular volumes and the extent of remodeling? $37-39$ Using this method, we demonstrated that the non-ischemic LV wall increased its contractility $30 \mathrm{~min}$ after coronary ligation and although the LV dimensions were not dilated at that time point, the septal ventricular myocardium might have been affected by the hyperkinetic status. On the other hand, the $\mathrm{RV}$ wall motion did not change and, interestingly, the RV dilated after coronary ligation, suggesting that the RV wall was stretched in the infarcted rat heart. After MI, the increased activities of the MAPKs followed these ventricular morphological changes, so increased myocardial contractility or increased wall tension by stretching may activate myocardial MAPKs. Thus, these signal transduction systems may be partially activated by the mechanical stress in AMI and may contribute to the subsequent ventricular remodeling.

The present study did not enable us to elucidate the reason for the differential activation of p44ERK and p42ERK or for the differential time course of MAPKs activation between ischemic and non-ischemic myocardium. However, a previous study showed that the activity of cardiac p44ERK was greater than p42ERK after angiotensin II infusion?22 Although the activation time course of the JNKs was similar between the 2 ventricles, the high-dose angiotensin II infusion demonstrated differential ERKs activation between the left and right ventricles. Taken together with our evidence, p44ERK and p42ERK, including the JNKs, may play a different role in cardiac tissue.

AP-1 DNA binding activity is induced by a wide array of stimuli, including growth factors, cytokines, neurotransmitters and cellular stress. The transcription factor AP-1 is the best-studied target of the signal transduction cascades of MAPKs. ERKs and JNKs can phosphorylate the TCF/Elk1 transcription factor, which forms ternary complexes with SRF, leading to the induction of c-fos expression. JNKs have been shown to increase c-Jun transcriptional activity by phosphorylating c-Jun on 2 critical $\mathrm{N}$-terminal serines ${ }^{40}$ AP-1 proteins, such as c-Jun and c-Fos, are reported to become homo- or hetero-dimerized in order to bind to the specific sequence in the enhancers of the various genes and then regulate their expression. Thus, the activation of ERKs and JNKs is likely to activate AP-1. However, little is known regarding whether MAPKs can activate AP-1 in $\mathrm{MI}$ in rats. In the present study, we found that AP-1 DNA binding activity was augmented in both the infarcted and non-infarcted myocardium. Supershift analysis with anti-cFos or anti-c-Jun antibody indicated that myocardial AP-1 binding complexes activated by ischemia contained c-Fos and c-Jun proteins.

In conclusion, we have shown the first in vivo evidence that ERKs, JNKs and p38MAPK are activated in the nonischemic region and RV of a rat heart infarcted after coronary artery ligation. The time courses of activation of myocardial MAPKs differed in the IM, non-infarcted SW and the RV. Echocardiography showed hyperkinetic motion in the non-ischemic SW and dilatation of the RV after MI. These results suggest that acceleration of workload and myocardial stretch may partially induce the activation of MAPKs, as well as the ischemia, in AMI.

\section{Acknowledgments}

We thank Doctors Ujino and Izutani for their valuable technical assistance and opinions, and Emi Utsunomiya, Chinami Kobata, Mihoko Watanabe, and Harumi Baba for their assistance with the manuscript.

\section{References}

1. Weisman HF, Bush DE, Mannisi JA, Bulkley BH: Global cardiac remodeling after acute myocardial infarction: A study in the rat model. J Am Coll Cardiol 1985; 5: 1355-1362

2. McKay RG, Pfeffer MA, Pasternak RC, Markis JE, Come PC, Nakao S, et al: Left ventricular remodeling after myocardial infarction: A corollary to infarct expansion. Circulation 1986; 74: 693-702

3. Pfeffer MA, Braunwald E: Ventricular remodeling after myocardial infarction: Experimental observations and clinical implications. Circulation 1990; 81: 1161-1172

4. White HD, Norris RM, Brown MA, Brandt PW, Whitlock RM, Wild CJ: Left ventricular end-systolic volume as the major determinant of survival after recovery from myocardial infarction. Circulation 1987; 76: $44-51$

5. Bolognese L, Cerisano G: Early predictors of left ventricular remodeling after acute myocardial infarction. Am Heart J 1999; 138: S79S83

6. Anversa P, Loud AV, Levicky V, Guideri G: Left ventricular failure induced by myocardial infarction. I. Myocyte hypertrophy. Am J Physiol 1985; 248: H876-H882 
7. Hanatani A, Yoshiyama M, Kim S, Omura T, Ikuno Y, Takeuchi K, et al: Assessment of cardiac function and gene expression at an early phase after myocardial infarction. Jpn Heart J 1998; 39: 375-388

8. Shimizu N, Yoshiyama M, Omura T, Hanatani A, Kim S, Takeuchi $\mathrm{K}$, et al: Activation of mitogen-activated protein kinases and activator protein-1 in myocardial infarction in rats. Cardiovasc Res 1998; 38: $116-124$

9. Kim S, Iwao H: Activation of mitogen-activated protein kinases in cardiovascular hypertrophy and remodeling. Jpn J Pharmacol 1999; 80: $97-102$

10. Gottlieb RA, Burleson KO, Kloner RA, Babior BM, Engler RL: Reperfusion injury induces apoptosis in rabbit cardiomyocytes. J Clin Invest 1994; 94: $1621-1628$

11. Ma XL, Kumar S, Gao F, Louden CS, Lopez BL, Christopher TA, et al: Inhibition of p38 mitogen-activated protein kinase decreases cardiomyocyte apoptosis and improves cardiac function after myocardial ischemia and reperfusion. Circulation 1999; 99: 1685-1691

12. Roulston A, Reinhard C, Amiri P, Williams LT: Early activation of c-Jun N-terminal kinase and p38 kinase regulate cell survival in response to tumor necrosis factora. J Biol Chem 1998; 273: 10232 10239

13. Gidh-Jain M, Huang B, Jain P, Gick G, El-Sherif N: Alterations in cardiac gene expression during ventricular remodeling following experimental myocardial infarction. J Mol Cell Cardiol 1998; 30: $627-637$

14. Fishbein MC, Maclean D, Maroko PR: Experimental myocardial infarction in the rat: Qualitative and quantitative changes during pathologic evolution. Am J Pathol 1978; 90: 57-70

15. Schreiber E, Matthias P, Muller MM, Schaffner W: Rapid detection of octamer binding proteins with 'mini-extracts', prepared from a small number of cells. Nucleic Acids Res 1989; 17: 6419

16. Kim S, Murakami T, Izumi Y, Yano M, Miura K, Yamanaka S, et al: Extracellular signal-regulated kinase and c-Jun NH2-terminal kinase activities are continuously and differentially increased in aorta of hypertensive rats. Biochem Biophys Res Commun 1997; 236: 199 204

17. Lee W, Mitchell P, Tjian R: Purified transcription factor AP-1 interacts with TPA-inducible enhancer elements. Cell 1987; 49: 741-752

18. Seko Y, Takahashi N, Tobe K, Kadowaki T, Yazaki Y: Hypoxia and hypoxia/reoxygenation activate p65PAK, p38 mitogen-activated protein kinase (MAPK), and stress-activated protein kinase (SAPK) in cultured rat cardiac myocytes. Biochem Biophys Res Commun 1997; 239: 840-844

19. Seko Y, Tobe K, Ueki K, Kadowaki T, Yazaki Y: Hypoxia and hypoxia/reoxygenation activate Raf-1, mitogen-activated protein kinase kinase, mitogen-activated protein kinases, and S6 kinase in cultured rat cardiac myocytes. Circ Res 1996; 78: 82-90

20. Bogoyevitch MA, Gillespie-Brown J, Ketterman AJ, Fuller SJ, BenLevy R, Ashworth A, et al: Stimulation of the stress-activated mitogen-activated protein kinase subfamilies in perfused heart. p38/RK mitogen-activated protein kinases and c-Jun N-terminal kinases are activated by ischemia/reperfusion. Circ Res 1996; 79: $162-173$

21. Kim S, Izumi Y, Yano M, Hamaguchi A, Miura K, Yamanaka S, et al: Angiotensin blockade inhibits activation of mitogen-activated protein kinases in rat balloon-injured artery. Circulation 1998; 97: 1731 1737

22. Yano M, Kim S, Izumi Y, Yamanaka S, Iwao H: Differential activation of cardiac c-Jun amino-terminal kinase and extracellular signalregulated kinase in angiotensin II-mediated hypertension. Circ Res 1998; 83: 752-760

23. Izumi $\mathrm{Y}$, Kim $\mathrm{S}$, Murakami T, Yamanaka S, Iwao H: Cardiac mitogen-activated protein kinase activities are chronically increased in stroke-prone hypertensive rats. Hypertension 1998; 31: 50-56

24. Zechner D, Craig R, Hanford DS, McDonough PM, Sabbadini RA, Glembotski CC: MKK6 activates myocardial cell NF-kappaB and inhibits apoptosis in a p38 mitogen-activated protein kinase-dependent manner. J Biol Chem 1998; 273: 8232-8239

25. Kudoh S, Komuro I, Mizuno T, Yamazaki T, Zou Y, Shiojima I, et al: Angiotensin II stimulates c-Jun NH2-terminal kinase in cultured cardiac myocytes of neonatal rats. Circ Res 1997; 80: 139-146

26. Lazou A, Sugden PH, Clerk A: Activation of mitogen-activated protein kinases (p38-MAPKs, SAPKs/JNKs and ERKs) by the Gprotein-coupled receptor agonist phenylephrine in the perfused rat heart. Biochem J 1998; 332: 459-465

27. Ramirez MT, Sah VP, Zhao XL, Hunter JJ, Chien KR, Brown JH: The MEKK-JNK pathway is stimulated by a-1-adrenergic receptor and ras activation and is associated with in vitro and in vivo cardiac hypertrophy. J Biol Chem 1997; 272: 14057-14061

28. Assefa Z, Vantieghem A, Declercq W, Vandenabeele P, Vandenheede JR, Merlevede W, et al: The activation of the c-Jun N-terminal kinase and p38 mitogen-activated protein kinase signaling pathways protects HeLa cells from apoptosis following photodynamic therapy with hypericin. J Biol Chem 1999; 274: 8788-8796

29. Meldrum DR, Dinarello CA, Cleveland JC Jr, Cain BS, Shames BD, Meng X, et al: Hydrogen peroxide induces tumor necrosis factoramediated cardiac injury by a p38 mitogen-activated protein kinasedependent mechanism. Surgery 1998; 124: 291-296 (Discussion 297)

30. Komuro I, Kudo S, Yamazaki T, Zou Y, Shiojima I, Yazaki Y: Mechanical stretch activates the stress-activated protein kinases in cardiac myocytes. FASEB J 1996; 10: 631-636

31. McDonough PM, Hanford DS, Sprenkle AB, Mellon NR, Glembotski CC: Collaborative roles for c-Jun N-terminal kinase, c-Jun, serum response factor, and $\mathrm{Sp} 1$ in calcium-regulated myocardial gene expression. J Biol Chem 1997; 272: 24046-24053

32. Bogoyevitch MA, Ketterman AJ, Sugden PH: Cellular stresses differentially activate c-Jun N-terminal protein kinases and extracellular signal-regulated protein kinases in cultured ventricular myocytes. J Biol Chem 1995; 270: 29710-29717

33. McAlpine HM, Morton JJ, Leckie B, Rumley A, Gillen G, Dargie HJ: Neuroendocrine activation after acute myocardial infarction. $\mathrm{Br}$ Heart J 1988; 60: $117-124$

34. Dargie HJ, McAlpine HM, Morton JJ: Neuroendocrine activation in acute myocardial infarction. J Cardiovasc Pharmacol 1987; 9: S21S24

35. Takemoto Y, Yoshiyama M, Takeuchi K, Omura T, Komatsu R, Izumi Y, et al: Increased JNK, AP-1 and NF-kappa B DNA binding activities in isoproterenol-induced cardiac remodeling. J Mol Cell Cardiol 1999; 31: 2017-2030

36. Harada K, Komuro I, Zou Y, Kudoh S, Kijima K, Matsubara H, et al: Acute pressure overload could induce hypertrophic responses in the heart of angiotensin II type 1a knockout mice. Circ Res 1998; 82: $779-785$

37. De Castro S, Agati L, Cartoni D, Papetti F, Beni S, Adorisio R, et al: Harmonic imaging with Levovist for transthoracic echocardiographic reconstruction of left ventricle in patients with post-ischemic left ventricular dysfunction and suboptimal acoustic windows. J Am Soc Echocardiogr 2000; 13: 139-145

38. Hundley WG, Kizilbash AM, Afridi I, Franco F, Peshock RM, Grayburn PA: Administration of an intravenous perfluorocarbon contrast agent improves echocardiographic determination of left ventricular volumes and ejection fraction: Comparison with cine magnetic resonance imaging. J Am Coll Cardiol 1998; 32: 14261432

39. Shim WJ, Lee EM, Hwang GS, Ahn JC, Song WH, Lim DS, et al: Microvascular integrity as a predictor of left ventricular remodeling after acute anterior wall myocardial infarction. J Korean Med Sci 1998; 13: 466-472

40. Minden A, Lin A, Smeal T, Derijard B, Cobb M, Davis R, et al: cJun N-terminal phosphorylation correlates with activation of the JNK subgroup but not the ERK subgroup of mitogen-activated protein kinases. Mol Cell Biol 1994; 14: 6683-6688 